\title{
Research on Inclusive Development Path of Shaanxi Province
}

\author{
Jing Zhao ${ }^{1}$ Shanshan Wang ${ }^{2}$ \\ ${ }^{1}$ Xi'an University of Science and Technology, Yanta Road No. 58, Xi'an, Shaanxi, China \\ ${ }^{2}$ Xi'an University of Science and Technology, Yanta Road No. 58, Xi'an, Shaanxi, China
}

\begin{abstract}
It is significant that inclusive development to Shaanxi's coordinated development of economy and society. Shaanxi province faces a series of problems in the process development. These problems hamper the Shaanxi's economy and society development to some extent. Combining the theoretical analysis and empirical approach, the causes which affect economic and social development of Shaanxi were analyzed, then put forward the suggestions to promote the inclusive development of Shaanxi province.
\end{abstract}

Keywords: Shaanxi; economy; society; inclusive development

\section{Introduction}

In April 2011, Hu Jintao proposed the term "inclusive development" in the Boao Forum for Asia. This idea causes widespread discussion in the academy circles. But up to now there has no unified connotation of the conception of "inclusive development". This article combined the opinions from many experts and scholars, think that inclusive development is based on the sustainable economic growth, paying more attention to maintain social fairness and justice, reducing poverty, narrowing the gap between rich and poor, safeguarding the interests of the social vulnerable groups, and making everyone can participate in economic development, and sharing the achievements of econom- ic development reasonably, and transforming the mode of economic development and making economy, society, resources and ecological environment in harmony.

Under the development of the west regions, Shaanxi province has made considerable development in economy, society and so on. Now, Shaanxi province becomes the economic center, trade center, education center and cultural center of western regions, Shaanxi is very important in China's scientific research, higher education, national defense science and technology industry and hightech industry. But at the same time, there are some problems in Shaanxi, such as there still are a lot of poor people, the gap between urban and rural areas is gradually widening, social security level is not high, the ecological environment seriously damaged, the development of the three industries is disharmony, the gap between different regions gap is larger, these problems have restricted the inclusive development of Shaanxi province.

\section{Inclusive Development Status of Shaanxi province}

In recent years, Shaanxi province stepped up its investment in poverty, and has achieved positive results; Actively promoting economic development, promoting urban and rural income to further; according to the national tax duty mode reform, resources also has carried on the reform of taxes and fees system; pay at- 
tention to the importance of protecting ecological environment; In the aspect of regional development, Shaanxi increased the investment of southern region. But Shaanxi also faces many problems.

First, there still are a lot of poor people. In 2010, Shaanxi has 50 key national poverty-stricken counties, 27 provincial key poverty-stricken counties. Shaanxi has 107 counties (city, area), the percent of key national poverty-stricken counties and the percent of provincial key povertystricken counties is $46.7 \%, 25.2 \%$. Therefore, the task to relieve from poverty is quite formidable. The distributions of poor counties in Shaanxi in 2010 are showed in table 1 .

Table1. the distribution of poor counties in Shaanxi in 2010

\begin{tabular}{|c|c|c|}
\hline $\begin{array}{c}\text { The name of } \\
\text { the city }\end{array}$ & $\begin{array}{c}\text { key national } \\
\text { poverty-stricken } \\
\text { counties[units] }\end{array}$ & $\begin{array}{c}\text { provincial key } \\
\text { poverty-stricken } \\
\text { counties[units] }\end{array}$ \\
\hline Yulin & 10 & 2 \\
\hline Yan'an & 6 & 7 \\
\hline Tongchuan & 3 & 0 \\
\hline Baoji & 3 & 5 \\
\hline Xianyang & 5 & 1 \\
\hline Xi'an & 0 & 1 \\
\hline Weinan & 3 & 5 \\
\hline Hanzhong & 5 & 4 \\
\hline Ankang & 8 & 2 \\
\hline Shangluo & 7 & 0 \\
\hline
\end{tabular}

Data source: Shaanxi poverty alleviation and development office

Second, the gap between urban and rural areas is gradually widening. In the "11th five-year plan" period, Shaanxi significantly improved its economic strength, the GDP reached 1.002153 trillion Yuan in 2010; Per capita GDP is more than 4000 Yuan, ranked first in the western provinces. During 2005-2010, Shaanxi urban residents disposable income has increased from 8000 Yuan to 16000 Yuan, the growth of consumption has increased from 7000 Yuan to 11000 Yuan, farmer's per capita net income and life consumption spending remained between 2000-4000 Yuan, the growing rate is not sharp. According to data shows, in Shaanxi, urban and rural residents income gap is gradually expanding, has reached more than five times [1].

Third, social security level is not high. The 2012 statistics bulletin of the national economy and social development of Shaanxi province has showed that, the population of Shaanxi has reached 37.5309 million, the population of urban is 18.773 million, accounted for $50.02 \%$, and the population of country is 18.7579 million, accounting for $49.98 \%$. at the end of 2012, 3.3914 million people attended unemployed insurance, accounted for $18.10 \%$ in urban; 5.8281 million people took part in the urban pension insurance, accounting for $31.05 \%$; 11.1881 million people participated in urban basic health insurance, accounting for $59.60 \%$; 3.504 million people participated in industrial injury insurance, accounting for $18.67 \%$; 2.2366 million people participated in birth insurance, accounting for $11.91 \%$. In villages, 2.057 million people took part in the minimum living standard system, accounting for $10.97 \%$; people who participated the Five Guaranteed has reached 152000 , accounting for $0.81 \%$ of the rural population. From the data above, no matter in urban or rural, Shaanxi's social security level is not very high.

Fourth, the ecological environment seriously damaged. In 2010, the entire province's GDP energy consumption is 1.28 tons of standard coal / ten thousand yuan, higher than the national standard 1.05 tons of standard coal / ten thousand yuan, ranked 16th in the China. Compared with the national medium developed provinces, resource utility ratio is low, the comprehensive utilization ratio of coexisted minerals is less than $40 \%$, the coal recovery rate is only $30 \%-50 \%$, oil recovery rate is lower than the national average level; solid waste comprehensive utilization rate is $40 \%$, industrial water reuse rate is approximately $50 \%$. COD 
and $\mathrm{SO} 2$ emissions are more than or close to environmental capacity [2].

Fifth, the development of the three major industries is disharmony. Preliminary accounting, in Shaanxi province in 2012, the GDP is 1.445118 trillion Yuan, increased $12.9 \%$ compared with last year. Primary industry added value 137.016 billion Yuan, accounting for the proportion of GDP is 9.5\%; Secondary industry added value 807.542 billion Yuan, accounting for 55.9\%; Tertiary-industry added value 500.56 billion Yuan, accounting for $34.6 \%$. From figure 1, we can obviously see that the secondary industry's contribution to GDP is the largest, reached more than $50 \%$, and as absorb to social surplus labor force, tertiaryindustry is small, and the proportion of tertiary-industry in the developed countries is generally above $70 \%$.

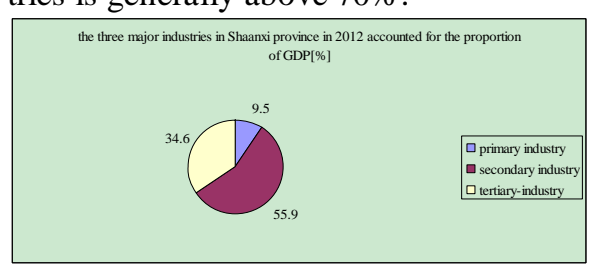

Figure1.the three major industries in Shaanxi province in 2012 accounted for the proportion of GDP

Data sources: the 2012 statistics bulletin of the national economy and social development in Shaanxi province, China

Sixth, the gap between different regions is larger. According to the geographical environment and humanistic folk, Shaanxi province can be divided into three regions: Shanbei, Guanzhong and Shannan. Shanbei mainly includes Yulin and Yan 'an, Guanzhong includes Tongchuan, Xian yang, Wei Nan, Xi'an, Baoji, and Yangling demonstration zone; Shannan includes Hanzhong, Ankang and Shangluo. Table 2 shows the GDP of three regions in Shaanxi from 2007 to 2012, we can find that for the largest contribution to the economic development is
Guanzhong, next is Shanbei, the last is Shannan.

Table2. the GDP of three regions in Shaanxi from 2007 to 2012

[One hundred million Yuan]

\section{The Reason of Shaanxi's Uninclusive Development}

First, the different economic development level lead to the reduced demand for primary products. According to Engel's law, during the family income increasing, the cost on food will be declined. By a logi-

\begin{tabular}{|c|c|c|c|}
\hline Year & 2007 & 2008 & 2009 \\
\hline Shanbei & 651.48 & 804.88 & 915.06 \\
\hline Guanzhong & 3610.31 & 4523.39 & 5235.86 \\
\hline Shannan & 1443.44 & 1933.60 & 2030.57 \\
\hline Year & 2010 & 2011 & 2012 \\
\hline Shanbei & 1122.66 & 1417.52 & 1724.28 \\
\hline Guanzhong & 6352.90 & 7667.82 & 8963.36 \\
\hline Shannan & 2642.09 & 3405.60 & 4040.24 \\
\hline
\end{tabular}

cal extension of this point, when the country developed rapidly, the expenditure for buying food and so on for everyone in the country (or average spending) will be smaller and smaller, and then it will inevitably lead to the proportion of food and other commodity prices falling down. With the development of technology, the emergence of various alternatives, synthetics would further reduce the price of primary products. Many families' income comes from producing or processing primary products and this phenomenon will increase the emergence of poverty.

Second, the city and the country occupy different resources. To urban residents, their living conditions, working conditions are superior to the people in rural areas. The general level of wages for urban dwellers is higher than rural residents; salary is the main source of their income. 
For farmers, although the salary income has increased year by year, the family business cash income is still the first source of family income; the income level of high or low largely depends on the stand of their own business operation. At the same time, urban residents can enjoy "Five social insurance and one housing fund "or " three insurances and one fund ", the farmers only have minimum living guarantee, social security level is low.

Third, the social security expenditure is too low. The fiscal expenditure in Shaanxi in 2012 was 359.139 billion yuan, the spending is as follows: generally public service 41.472 billion yuan, national defense and public security 15.364 billion yuan, education 69.333 billion yuan, science and technology 3.441 billion yuan, culture and sports and media 9.176 billion yuan, social security and employment 42.445 billion yuan, medical and health care 21.926 billion yuan, energy conservation and environmental protection 9.172 billion yuan, urban and rural community affairs 18.649 billion yuan, agriculture, forestry and water affairs 37.753 billion yuan, transportation 24.722 billion yuan, housing security 15.294 billion yuan [3]. Spending of social security and employment accounted for only $11.82 \%$ in the finance expenditure.

Fourth, the way of energy resources tax collection is not reasonable. Although beginning December 1, 2010, Shaanxi carried on the crude oil, natural gas resource tax reform. The energy resources tax is on an ad Valorem Basis. But Shaanxi has the largest coal resources in the whole country. The coal resource tax is still on a specific basis according to 3.2 yuan/tons of standard, resource tax lever and price lever cannot effectively play a regulating differential rent and timely reflect the role of coal market price changes, the effect of tax to cut down and make the external diseconomies in coal mining is weakening [4].

Fifth, the economy development excessively depends on energy resources. Shaanxi has the most energy resources in our country, the Shanbei energy chemical industry base has a lot of coal, oil and natural gas, respectively accounted for $23 \%, 17 \%$ and $27 \%$ in the nation[5]. This will aggravate the dependence on energy resources in Shaanxi, energy resources is the blood of industrial development, this will to led to the development of secondary industry.

Sixth, the geographical environment differences are increasing the gap between rich and poor. Shanbei has a lot of energy resources, the development of energy resources is benefit to local related industry; the terrain of Guanzhong is very flat, the transportation is convenient, cultural background is deep-rooted. $\mathrm{Xi}$ 'an , as a provincial capital city is also located here, the effect of political center will speed up the development of Guanzhong; As for Shannan, due to the limitation of geographic and topographic conditions, economic development level is low.

\section{Suggestions for Promoting Shaan- xi's Inclusive Development}

First, actively develop modern agriculture. There are many national famous specialties, such as Luochuan apple, Zhouzhi kiwi, Lintong pomegranate, Yanchuan jujube, Zhen' an chestnut and so on in Shaanxi. Aiming at the low additional value content of these characteristic agricultural products, we can adopt the following measures. Firstly, to actively promote experiment stations and research institutes of these fruit industries to cooperate with those in the province and even national well-known agricultural universities, to actively explore and cultivate 
new technology of fruit industry development in cultivation, breeding, preservation, cold storage, transportation, etc., and reduce business operating costs. Secondly, to construct plantation demonstration areas, make use of modern planting concept to implement integrated management in the process of cultivation, production, processing and sales, and thus to drive the modernization of the development of fruit industries in the area and even the entire province from the typical demonstrations. Thirdly, to combine the plantation demonstration areas with tourism and leisure resort areas, to drive the two-way development of agriculture and tourism.

Second, establish the sound social security system. Aiming at the conditions of gradually widening gap between urban and rural areas and low social security level, we must further strengthen fiscal transfer payment, and actively build social security mechanism which adapts to the economic development level, to gradually achieve the complete coverage of urban and rural in basic endowment, basic medical care and minimum living security, and gradually enhance security standards according to the actual situation of economic development. We can increase basic living security of lowincome people according to the actual situation of price rising and substantially increase financial investment of education, and further promote educational equity. Vigorously strengthen the construction of medical and health service system and the integration of urban and rural public health services. Implement the income doubling plan of urban and rural residents, make the disposable income of urban residents at or above the national average leve [6].

Third, reform the calculation about coal resource taxation. As the way of calculation and collection of resource taxation such as oil and gas, we can carry out the calculation on price instead of amount in coal resource taxation. To set up tax rates should fully consider the tax burden of enterprises, prices of relevant industry, local tax revenue and external diseconomy which are led by the exploitation of coal. In this way, it fully reflects the scarcity characteristics of coal resource, and strengthens the control function of coal resource tax as a tax revenue lever and a price lever. At the same time, we should strengthen the regulation of resource tax expenditure and set up a special account to treat the coming problems such as vegetation destruction, groundwater pollution, and air pollution of the mining area, which are brought by the exploitation of coal.

Fourth, optimize the industrial structure. According to the actual situation of the development of Shaanxi, industry structure should be optimized and the coordination of the development of the three major industries should be promoted. We should increase the intensity of investment in primary industry and the tertiary-industry, and thus to promote the harmonious development of the three major industries. In terms of agriculture, we should transform the traditional agriculture by using modern management ideas, optimizing the industrial structure of agriculture, improving the quality of agricultural products, increasing the deep processing of agricultural products to adapt to the change of market demand, providing a variety of products to meet the needs of consumers. In respect of industry, we should optimize the industrial structure, especially focus on the industrial upgrading of three pillar industries of energy-chemical industry, equipment manufacturing industry, and non-ferrous metallurgy industry, to make the energychemical industry transform from primary development to the deep development. While orderly exploiting underground 
resources, we should introduce resources of surrounding provinces for further processing and actively develop energyrelated equipment manufacturing industry. To vigorously develop the emerging strategic industries, and strive to make a breakthrough in new energy, new materials, life science, biological medicine, information network to get ahead in the national level, to form a new economic growth point [7]. Regarding the tertiaryindustry, as a major tourism province, Shaanxi can make cooperation with the surrounding provinces to fully play the role in "west triangle" (Chongqing, Chengdu, Xi 'an).

Fifth, fully bring the characteristic superiority of every region into development. Different development measures should be taken according to the special conditions of the three major areas of Shaanxi. As for Northern Shaanxi, According to its characteristics, we can continue to develop the energy industry while paying attention to the local environment protection. We should pay attention to the deep processing of products and make use of advanced science and technology to improve the recovery rate of energy resources and reduce the waste of energy resources to guarantee the sustainable development of future generations. The characteristics of Guanzhong, we can develop high-tech industry, equipment manufacturing industry, aerospace industry and mineral mining and processing industry. And the speed of the base construction of the advanced manufacturing industry of GuanzhongTianshui economic zone should be further accelerated. Shannan is located in the headwaters area of Han River, Jialing River and Dan River and the Yellow River's branch, Nanluo River. Qinling wild zoo is located there. And it is also an important area to store the noble metal, rare metal and non-metallic materials. The rare metal manufacturing industry and characteristic tourism industry can be developed. And it can take the way of circular economy development according to "Planning of Industry Development of Circular Economy of Shannan" [8].

\section{Acknowledgements}

This work was financially supported by the Project of Shaanxi Provincial Association of Social Sciences (2012C065), Humanities and Social Science Project Funded by Shaanxi Provincial Education Department (12JK0140).

\section{References}

[1,2,6] Shanqin Yang, Shi Ying and Chengrong Pei: The report of Shaanxi's economic development (2012) (social sciences press, Beijing 2012), In Chinese

[3] Information on http://www. Shaanxi .gov.cn, In Chinese

[4] Zongzhe Ren, Shi Ying and Chengrong Pei: The report of Shaanxi's economic development (2013) (social sciences academic press, Beijing 2013), In Chinese

[5] Gao Wei, Zhiqiang Ru, In: Exploration \& Research of Finance, volume 12 (2007), P.12. In Chinese

[7] Yongyi Wu, Mingmei Fang, in: Journal of western financial accounting, volume 6(2012), p.4-7. In Chinese

[8] Shuhui Li, in: Journal of Xi'an University of Posts and Telecommunications, volume 7(2011), p.82-86. In Chinese 